\title{
Recent Advances in the Treatment of Gliomas: The Multimodal Care Therapy
}

\author{
Omar Ibrahim ${ }^{1 *}$ D, Mohamed A, Hafez ${ }^{1}$, Helmy Abdel Haleem ${ }^{1}$, Hussein El Maghraby ${ }^{2}$ \\ ${ }^{1}$ Department of Neurosurgery, Faculty of Medicine, Cairo University, Giza, Egypt; ${ }^{2}$ Department of Neurosurgery, Faculty of \\ Medicine, University of Coventry, Coventry, England
}

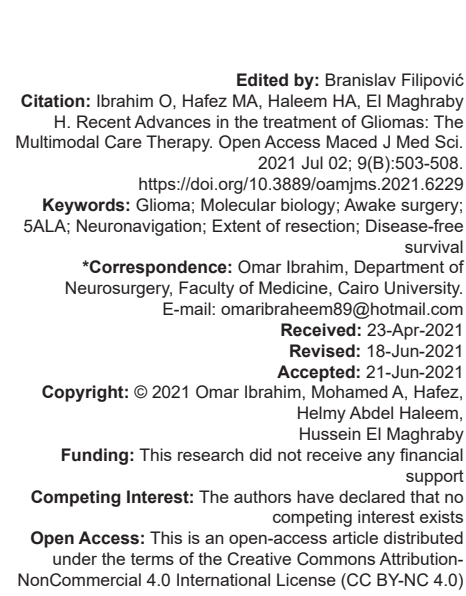

\section{Introduction}

Gliomas are a class of tumors which arise from the supporting structures of the brain which are astrocytes and oligodendrocytes. They range in behavior from benign lesions with distinct borders such as juvenile pilocytic astrocytoma, curable with surgical resection alone, to more diffusely infiltrative cancerous lesions, astrocytoma, oligodendrogliomas, and glioblastoma (GBM), all uniformly lethal in a matter of several to many years [1].

They are the most common primary brain tumors in adults; they represent nearly $80 \%$ of all primary malignant brain tumors, with poor prognosis in their high-grade histotypes [2].

According to the current WHO grading system, high grades include Grade III and IV lesions. One-year survival rate for high-grade gliomas (HGG) is $53.7 \%$, while the 2-year survival rate for these patients is only $14.6 \%$ [3].

GBM is the most devastating primary malignancy of the central nervous system in adults. At present, standard treatment consists of maximal safe surgical resection or a diagnostic biopsy, followed by radiotherapy (60 Grays) with concomitant daily temozolomide chemotherapy, followed by maintenance treatment with temozolomide for 6-12 months [1].

Low-grade gliomas (LGGs) constitute approximately $15 \%$ of the nearly primary glial brain tumors diagnosed in adults each year [4]. The majority of LGGs are detected in healthy patients with good neurologic status following a seizure [5]. LGGs tend to occur in locations adjacent to eloquent areas of the cortex [6]. A common location for these tumors in adults is in the supratentorial region, frequently involving the supplementary motor cortex and insula [7].

Due to their infiltrative nature and their appearance looking like normal brain, LGGs require a combination of regimens from resection, chemotherapy, and radiation. Most LGGs will gradually evolve into higher-grade gliomas and likely patients will die from the disease [8], [9].

Median survival for patients with LGGs ranges from 5.6 to 13.3 years and is dependent on specific histology and molecular characteristics [10].

Treatment options include surgery, radiotherapy, and chemotherapy. Surgical intervention 
is generally performed with the goal of maximum safe resection and aids in diagnosis by providing tissue for molecular testing (1p19q codeletion, IDH, ATRX [ $\alpha$-thalassemia/mental-retardation- syndrome-X-linked] mutations).

Radiation is typically reserved for patients considered to be at "high risk" (for example, patients over 40 years old or patients with an incomplete resection) or with progressive disease [11].

Several variables positively affect the prognosis for patients diagnosed with gliomas: These include young age, tumor location, radiological features, recurrence, and the opportunity to perform an adjuvant therapy in the postoperative course [12].

\section{Patients and Methods}

This is an observational prospective study of 50 patients of glioma that was treated through microscopic resection at University Hospitals Coventry and Kasr AL Ainy University Hospitals. All cases were not operated on before. Careful history taking, thorough neurological examination, and pre- and post-operative radiological evaluation were done for all patients. Patients with an unstable neurological condition or who were considered a poor medical risk after surgery resulting in Karnofsky Performance Scale score of below 70 were excluded from the study.

Pre-operative computed tomography (CT) scans of brain, magnetic resonance imaging (MRI) scans with IV contrast, perfusion-weighted imaging, and MR spectroscopy were performed to all patients, while functional MRI studies were done only for patients with lesions affecting eloquent areas of the brain.

Low-grade glioma patients were operated on using awake craniotomy technique, while high-grade glioma patients were operated on using intraoperative fluorescence-guided technique.

Before awake surgeries, the tasks that will be performed during surgery were rehearsed in the ward. Simulation of the surgical posture, equipment setup, and role sharing, as well as rehearsal of the tasks for the patient, surgeons, and anesthesiologists were also performed in the operating room.

In awake surgeries, a complete scalp block was done along the incision and around the incision using $1: 1$ mixture of $2 \%$ xylocaine with adrenaline $(20 \mathrm{ml})$ and $0.5 \%$ Marcaine $(20 \mathrm{ml})$.

Neuronavigation was used for optimizing the surgical approach to the tumor in the majority of our patients as well as cortical mapping for preservation of eloquent areas of the brain. Electrocortical stimulation mapping and subcortical white matter stimulation are used to establish a realtime functional map of the brain surface that allows the surgeon to delineate a safe boundary for tumor resection.

Resection was then performed, sparing the functional areas detected by stimulations, regularly given during the resection, to define precisely the interface between lesion and functional areas. At the end of the resection, cortical stimulations were repeated using the same electrical parameters (particularly, the same intensity) as before, to check the functional integrity of the pyramidal pathways again, with the same clinical criteria of evaluation used previously.

In fluorescence-guided surgery, a Zeiss OPMI Pentero microscope for neurosurgery with alternating white and blue light visualization mode was used. 5ALA was given orally to patients with a dose of $20 \mathrm{mg} / \mathrm{kg}$. One gram of 5ALA (Gliolan) was dissolved in $50 \mathrm{ml}$ of water and given $4 \mathrm{~h}$ before surgery to the patients.

Resection was carried out by switching liberally between white light and blue light modes of the surgical microscope. Because GBMs frequently feature necrosis, which either fluoresces weakly or not at all due to missing metabolism, resection was performed by dissecting marginal, fluorescing tissue outside of the area of frank necrosis. This strategy allowed surgery to be as efficient and quick as possible.

Post-operative CT scans and MRI were performed to all patients to detect the radiological extent of resection.

Tumors were subject to histopathological assessment and molecular biology studies for diagnostic and prognostic purposes. Low-grade glioma patients were put under oncological surveillance while high-grade glioma patients received a combination of radiation and chemotherapy.

All patients had regular follow-ups for the assessment of functional outcome following surgery, disease-free survival, and true survival status.

\section{Results}

The study included 50 patients, 31 males and 19 females, ages ranged from 21 to 75 years (mean age 47.5 years). The mean follow-up duration was 6 months with a range of 1-24 months.

The chief complaint was seizures in 22 cases (44\%), headache in 13 cases (26\%), dysphasia in 6 cases $(12 \%)$, and weakness in 5 cases $(10 \%)$ (Table 1$)$.

The most common tumor location was found to be in the frontal lobe in 29 patients (58\%) followed by the temporal lobe in 12 patients (24\%), parietal and 
occipital lobe in 4 patients each $(16 \%)$, and only one patient with a cerebellar tumor $(2 \%)$.

Thirty-six out of 50 patients $(72 \%)$ had a tumor affecting an eloquent area in the brain while only 14 patients had their tumors in non-eloquent areas $(28 \%)$. The left side of the brain was affected in 30 patients $(60 \%)$ while the right side tumors were found in 20 patients (40\%).

Table 1: Pre-operative presenting symptoms in 50 patients with glioma

\begin{tabular}{lll}
\hline Symptom & Number of patients & Percentage \\
\hline Seizures & 22 & 44 \\
Headache & 13 & 26 \\
Dysphasia & 6 & 12 \\
Weakness & 5 & 10 \\
Visual problems & 4 & 8 \\
\hline
\end{tabular}

Gross total resection was achieved in 28 patients (56\%), while debulking more than $50 \%$ was achieved in 22 patients (44\%) patients. A routine postoperative contrast-enhanced $\mathrm{MRI}$ and MRI perfusion were done in most patients within $72 \mathrm{~h}$ from surgery to determine the radiological extent of resection and the presence of any residual tumor.

In our series, 38 out of 50 patients (76\%) had not encountered any significant post-operative complications, while 4 patients $(8 \%)$ had transient weakness which improved during hospital stay, 4 patients ( $8 \%$ ) had post-operative wound collection, and only 1 patient $(2 \%)$ had post-operative photosensitivity following the use of intraoperative fluorescence.

Table 2: Lesion characteristics in $\mathbf{5 0}$ patients with glioma

\begin{tabular}{lll}
\hline Characteristic & Types & Percentage \\
\hline Pathology & LGG & 10 patients (20) \\
& AA & 5 patients (10) \\
Location & GBM & 35 patients (70) \\
& Frontal & 29 patients (58) \\
& Temporal & 12 patients (24) \\
& Parietal & 4 patients (16) \\
& Occipital & 4 patients (16) \\
Eloquence & Cerebellar & 1 patient (2) \\
& Eloquent & 36 patients (72) \\
\hline GBM: Glioblastoma, LGGs: Low-grade gliomas. & 14 patients (28) \\
\hline
\end{tabular}

Thirty-five patients (70\%) had their tissue pathology revealing GBM multiforme, 5 patients (10\%) were diagnosed with anaplastic astrocytoma, and 10 patients $(20 \%)$ with astrocytoma Grade 2 (Table 2 ). Molecular biology studies were only done to a certain number of patients due to financial reasons, so 21 out of 35 patients with GBM were found to be IDH wild type and 5 patients were IDH mutant type. Only five among low-grade glioma patients did molecular biology studies and four out of them were IDH mutant type and only one was IDH wild type.

As regards post-operative oncological treatment, 45 patients $(90 \%)$ needed to receive adjuvant therapy in the form of radical radiotherapy, chemotherapy, or a combination of both while only 5 patients (10\%) were put under oncological surveillance with no need for further intervention.

Mean true survival as well as disease-free survival of low-grade glioma patients were 40.5 months and all of our patients are still alive. On the other hand, the mean true survival for anaplastic astrocytoma (Grade 3) patients was 38 months and that of GBM (Grade 4) patients was 18.8 months.

\section{Discussion}

The management of glioma patients remains challenging and is often based on clinician experience and patient preference [42]. Treatment options have been limited and current research endeavors have not led to a cure for gliomas, however, clinical trials have contributed to a better understanding of the disease progression and improvements in patient outcomes to treatment [43].

It has been demonstrated that the patient factors (age, comorbidities, and Karnofsky score), tumor factors (tumor grade, tumor location, and lobes), and treatment factors (surgical methods and adjuvant therapy) were among the most significant predicting factors influencing overall survival [44].

As for LGG, early maximal safe resection is considered standard of care. Factors favoring early resection are the uncertainty about the radiological diagnosis, the assumption that resection will postpone malignant transformation and will improve overall survival [45].

In recent years, there has been a trend of favoring GTR in the treatment of LGGs and relevant studies published up to 2017 showed that GTR greatly increased the 5-year and 10-year survival of patients with LGGs. Twenty studies assessing the surgical outcomes of LGGs were analyzed, and results showed that patients with LGGs are expected to benefit from a greater extent of resection if their safety during the surgery can be ensured [46].

To achieve maximal safe resection, awake craniotomy technique was performed in our study for all eligible patients with low-grade glioma affecting an eloquent area in the brain as the precentral gyrus (motor strip), corticospinal tracts, Broca's speech area, Wernicke's speech area, or the brain stem.

The use of awake craniotomies in brain tumor surgery has been shown to decrease postoperative neurologic deficits and surgical morbidity while safely delineating an operative margin for resection [4].

Among our low-grade glioma patients, 8 out of 10 had an awake surgery using neuronavigation when available or needed. The integration of standard neuronavigation with functional non-invasive neuroimaging such as functional MRI or diffusion tensor imaging was helpful to improve post-operative functional outcome. 
Over the past decade, there was a large global interest in fluorescence-guided surgery (FGS) in patients with malignant brain tumors with the majority of these studies focusing on the use of 5-aminolevulinic acid (5-ALA) as a fluorescent pro-agent for FGS of malignant gliomas [27].

In this study, FGS was used in all patients with HGG to help the neurosurgeon to better distinguish the tumor margin and to improve the likelihood of complete resection.

During tumor resection, 5-ALA-induced fluorescence provides the neurosurgeon with realtime information for differentiating tumor from normal tissue that is independent of neuronavigation and brain shift [27].

5-ALA-induced tumor fluorescence helps in identification and resection of infiltrative glioma regions at the tumor margin which are typically not shown with pre-operative MRI in patients with malignant gliomas as gadolinium contrast enhancement relies on disruption of the BBB [27].

Using 5-ALA, the tumor is clearly visible in the surgical field; therefore, the only reason to leave tumor tissue behind should be that the tumor affects an eloquent area of the brain or areas whose lesion could produce a neurological deficit for the patient [26].

Surgical resection remains a critical component of the multimodality management of HGGs in local practice. The completeness of tumors resection significantly improves the effectiveness of adjuvant therapy [44].

The use of these advanced techniques played a big role in achieving maximum safe resection with no significant post-operative neurological deficit. Nine out of 10 patients with LGG had a gross total resection of their tumors while this was achieved in 24 out of 40 patients with HGG. The extent of resection was proved by postoperative MRI with contrast enhancement and perfusion MRI showing no residual.

A key prognostic factor in neurosurgical oncology is the extent of resection and despite limitations in the quality of data, mounting evidence suggests that more extensive surgical resection is associated with longer life expectancy for both low- and high-grade newly diagnosed gliomas [15], [43].

Early radiation for LGG has not demonstrated a survival benefit, but is associated with improved progression-free survival at 2,5 , and 10 years. The role of chemotherapy only remains less certain because no single chemotherapy regimen has yet emerged as the undisputed standard of care for patients with LGGs. A trial by Buckner et al. in 2016 demonstrated a 5.5-year median survival advantage and a progressionAQ6 free survival benefit from the addition of PCV chemotherapy to radiotherapy [42].

However, only three of the low-grade glioma patients included in this study had post-operative adjuvant therapy due to the presence of residual tumor on post-operative follow-up MRI and molecular biology studies revealing IDH wild-type LGG.

While in HGG, the addition of temozolomide to radiotherapy early in the course of the tumor provides a statistically significant and clinically meaningful survival benefit [1]. This was the standard oncological treatment for all HGG patients in this study.

The median survival of LGG in our study was 40.5 months while that of $A A$ and GBM patients was 38 months and 18.8 months, respectively. These numbers were comparable with the median survival of GBM and AA which were 12 months-15 months and 2 years-5 years based on current published data [44].

\section{Conclusion}

Advances in intraoperative technique, including neuro-navigation, intraoperative magnetic resonance imaging, intraoperative ultrasound, stimulation mapping techniques, and fluorescence-guided surgery, have all been developed to maximize tumor resection and minimize surgical morbidity for both low- and highgrade glioma.

Our study showed a significant clinical benefit for HGG patients in terms of overall survival by using 5 ALA guided surgery with better post-operative functional outcome when compared with the conventional surgical method.

The use of awake craniotomies in LGG surgery has been shown to decrease postoperative neurologic deficits and surgical morbidity while safely delineating an operative margin for resection.

\section{References}

1. Stupp R, Mason WP, van den Bent MJ, Weller M, Fisher B, Taphoorn MJB, et al. Radiotherapy plus Concomitant and Adjuvant Temozolomide for Glioblastoma. N Engl J Med [Internet]. 2005 Mar 10 [cited 2020 Jun 30];352(10):98796. Available from: http://www.nejm.org/doi/abs/10.1056/ NEJMoa043330

2. Maugeri R, Schiera G, di Liegro CM, Fricano A, lacopino DG, Di Liegro I. Aquaporins and brain tumors. Vol. 17, International Journal of Molecular Sciences. MDPI AG; 2016.

3. Chen B, Wang H, Ge P, Zhao J, Li W, Gu H, et al. Gross total resection of glioma with the intraoperative fluorescenceGuidance of fluorescein sodium. Int J Med Sci [Internet]. 2012 Oct 6 [cited $2020 \mathrm{Jul}$ 1];9(8):708-14. Available from: https:// pubmed.ncbi.nlm.nih.gov/23091408/

4. Hollon T, Hervey-Jumper SL, Sagher O, Orringer DA. Advances in the surgical management of low-grade glioma [Internet]. Vol. 25, Seminars in Radiation Oncology. W.B. Saunders; 2015 
[cited 2020 Jul 1]. p. 181-8. Available from: /pmc/articles/ PMC4460567/?report=abstract

5. Bondy ML, Scheurer ME, Malmer B, Barnholtz-Sloan JS, Davis FG, Il'yasova D, et al. Brain tumor epidemiology: Consensus from the Brain Tumor Epidemiology Consortium [Internet]. Vol. 113, Cancer. NIH Public Access; 2008 [cited 2020 Jul 1]. p. 1953-68. Available from: /pmc/articles/PMC2861559/?report=abstract

6. Duffau H, Capelle L. Preferential brain locations of lowgrade gliomas: Comparison with glioblastomas and review of hypothesis. Cancer [Internet]. 2004 Jun 15 [cited $2020 \mathrm{Jul}$ 1];100(12):2622-6. Available from: https://pubmed.ncbi.nlm.nih. gov/15197805/

7. Chang EF, Clark A, Jensen RL, Bernstein M, Guha A, Carrabba $G$, et al. Multiinstitutional validation of the University of California at San Francisco low-grade glioma prognostic scoring system: Clinical article. J Neurosurg [Internet]. 2009 Aug [cited $2020 \mathrm{Jul}$ 1];111(2):203-10. Available from: https://pubmed.ncbi.nlm.nih. gov/19267536/

8. Wijnenga MMJ, Mattni T, French PJ, Rutten GJ, Leenstra S, Kloet $F$, et al. Does early resection of presumed low-grade glioma improve survival? A clinical perspective. J Neurooncol. 2017;

9. Ramakrishna R, Hebb A, Barber J, Rostomily R, Silbergeld D. Outcomes in Reoperated Low-Grade Gliomas. Neurosurgery [Internet]. 2015 Aug 20 [cited 2020 Jul 1];77(2):175-84. Available from: https://pubmed.ncbi.nlm.nih.gov/25850601/

10. Buckner JC, Shaw EG, Pugh SL, Chakravarti A, Gilbert MR, Barger GR, et al. Radiation plus Procarbazine, CCNU, and Vincristine in Low-Grade Glioma. N Engl J Med [Internet]. 2016 Apr 7 [cited 2020 Jul 1];374(14):1344-55. Available from: http:// www.nejm.org/doi/10.1056/NEJMoa1500925

11. Weller M, van den Bent M, Tonn JC, Stupp R, Preusser M, Cohen-Jonathan-Moyal E, et al. European Association for NeuroOncology (EANO) guideline on the diagnosis and treatment of adult astrocytic and oligodendroglial gliomas [Internet]. Vol. 18, The Lancet Oncology. Lancet Publishing Group; 2017 [cited 2020 Jul 1]. p. e315-29. Available from: https://pubmed.ncbi. nIm.nih.gov/28483413/

12. Smith LGF, Nakano I. Fluorescence-guided brain tumor surgery. World Neurosurg [Internet]. 2012 Dec [cited $2020 \mathrm{Jul}$ 1];78(6):559-64. Available from: https://pubmed.ncbi.nlm.nih. gov/23041183/

13. Hadjipanayis CG, Widhalm G, Stummer W. What is the surgical benefit of utilizing 5-aminolevulinic acid for fluorescence-guided surgery of malignant gliomas? Neurosurgery. 2015.

14. Brown TJ, Bota DA, van Den Bent MJ, Brown PD, Maher E, Aregawi $\mathrm{D}$, et al. Management of low-grade glioma: a systematic review and meta-analysis. Neuro-Oncology Pract [Internet]. 2019 Jul 27 [cited 2020 Jun 30];6(4):249-58. Available from: https://academic.oup.com/nop/article/6/4/249/5076129

15. Young RM, Jamshidi A, Davis G, Sherman JH. Current trends in the surgical management and treatment of adult glioblastoma [Internet]. Vol. 3, Annals of Translational Medicine. AME Publishing Company; 2015 [cited 2020 Jun 30]. Available from: /pmc/articles/PMC4481356/?report=abstract

16. Ng WP, Liew BS, Idris Z, Rosman AK. Fluorescence-guided versus conventional surgical resection of high grade glioma: A single-centre, 7-year, comparative effectiveness study. Malaysian J Med Sci. 2017;

17. Wijnenga MMJ, Mattni T, French PJ, Rutten GJ, Leenstra S, Kloet $F$, et al. Does early resection of presumed low-grade glioma improve survival? A clinical perspective. J Neurooncol. 2017 May 1;133(1):137-46.

18. Xia L, Fang C, Chen G, Sun C. Relationship between the extent of resection and the survival of patients with low-grade gliomas: A systematic review and meta-analysis. BMC Cancer [Internet]. 2018 Jan 6 [cited 2020 Jun 30];18(1). Available from: /pmc/
articles/PMC5756328/?report=abstract

19. Schebesch KM, Brawanski A, Hohenberger C, Höhne J. Fluorescein sodium-guided surgery of malignant brain tumors: History, current concepts, and future projects. Turk Neurosurg. 2016;26:185-94. https://doi.org/10.5137/1019-5149. jtn.16952-16.0

PMid:26956810

20. Schwake M, Stummer W, Suero Molina EJ, Wölfer J. Simultaneous fluorescein sodium and 5-ALA in fluorescenceguided glioma surgery. Acta Neurochir. 2015;157(5):877-9. https://doi.org/10.1007/s00701-015-2401-0

PMid:25820632

21. Schebesch KM, Proescholdt M, Höhne J, Hohenberger C, Hansen E, Riemenschneider MJ, et al. Sodium fluoresceinguided resection under the YELLOW $560 \mathrm{~nm}$ surgical microscope filter in malignant brain tumor surgery a feasibility study. Acta Neurochir (Wien). 2013;155(4):693-9. https://doi. org/10.1007/s00701-013-1643-y

PMid:23430234

22. Neira JA, Ung TH, Sims JS, Malone HR, Chow DS, Samanamud JL, et al. Aggressive resection at the infiltrative margins of glioblastoma facilitated by intraoperative fluorescein guidance. J Neurosurg. 2017;127(1):111-22. https://doi. org/10.3171/2016.7.jns16232

PMid:27715437

23. Berger MS. The fluorescein-guided technique. Neurosurg Focus. 2014;36(2):E6.

PMid:24484259

24. Ferraro N, Barbarite E, Albert TR, Berchmans E, Shah AH, Bregy A, et al. The role of 5-aminolevulinic acid in brain tumor surgery: A systematic review. Neurosurg Rev. 2016;39(4):54555. https://doi.org/10.1007/s10143-015-0695-2

PMid:26815631

25. Zhao S, Wu J, Wang C, Liu H, Dong X, Shi C, et al. Intraoperative fluorescence-guided resection of high-grade malignant gliomas using 5-aminolevulinic acid-induced porphyrins: A systematic review and meta-analysis of prospective studies. PLoS One. 2013;8(5):e63682. https://doi.org/10.1371/journal. pone. 0063682

PMid:23723993

26. Díez Valle R, Solis ST. To what extent will 5-aminolevulinic acid change the face of malignant glioma surgery?. CNS Oncol. 2015;4(4):265-72. https://doi.org/10.2217/cns.15.10 PMid:26118538

27. Hadjipanayis CG, Widhalm G, Stummer W. What is the surgical benefit of utilizing 5-aminolevulinic acid for fluorescence-guided surgery of malignant gliomas? Neurosurgery. 2015;77(5):66373. https://doi.org/10.1227/neu.0000000000000929 PMid:26308630

28. Halani SH, Adamson DC. Clinical utility of 5-aminolevulinic acid $\mathrm{HCl}$ to better visualize and more completely remove gliomas. Onco Targets Ther. 2016;9:5629-42. https://doi.org/10.2147/ott. s97030

PMid:27672334

29. Masubuchi T, Kajimoto Y, Kawabata S, Nonoguchi N, Fujishiro T, Miyatake SI, et al. Experimental study to understand nonspecific protoporphyrin ix fluorescence in brain tissues near tumors after 5-aminolevulinic acid administration. Photomed Laser Surg. 2013;31(9):428-33. https://doi.org/10.1089/pho.2012.3469 PMid:23869519

30. Yamada S, Muragaki Y, Maruyama T, Komori T, Okada Y. Role of neurochemical navigation with 5-aminolevulinic acid during intraoperative $\mathrm{MRI}$-guided resection of intracranial malignant gliomas. Clin Neurol Neurosurg. 2015;130:134-9. https://doi. org/10.1016/j.clineuro.2015.01.005 


\section{PMid:25615582}

31. Hassan WM. The history of awake craniotomy in hospital universiti Sains Malaysia. Malays J Med Sci. 2013;20(5):67-9. PMid:24643321

32. Bulsara KR, Johnson J, Villavicencio AT. Improvements in brain tumor surgery: The modern history of awake craniotomies. Neurosurg Focus. 2005;8:e5. https://doi.org/10.3171/ foc.2005.18.4.6

PMid:15844868

33. Kim SS, McCutcheon IE, Suki D, Weinberg JS, Sawaya R, Lang FF, et al. Awake craniotomy for brain tumors near eloquent cortex: Correlation of intraoperative cortical mapping with neurological outcomes in 309 consecutive patients. Neurosurgery. 2009;64(5):836-45. https://doi.org/10.1227/01. neu.0000342405.80881.81 PMid:19404147

34. Sartorius CJ, Berger MS. Rapid termination of intraoperative stimulation-evoked seizures with application of cold Ringer's lactate to the cortex. J Neurosurg. 1998;88(2):349-51. https:// doi.org/10.3171/jns.1998.88.2.0349 PMid:9452250

35. Eseonu Cl, ReFaey K, Garcia O, John A, Quiñones-Hinojosa A, Tripathi P. Awake craniotomy anesthesia: A comparison of the monitored anesthesia care and asleep-awake-asleep techniques. World Neurosurg. 2017;104:679-86. https://doi. org/10.1016/j.wneu.2017.05.053

\section{PMid:28532922}

36. Sanai N, Mirzadeh Z, Berger MS. Functional outcome after language mapping for glioma resection. $\mathrm{N}$ Engl $\mathrm{J}$ Med. 2008;358(1):18-27. https://doi.org/10.1056/nejmoa067819 PMid:18172171

37. Laws ER, Taylor WF, Clifton MB, Okazaki H. Neurosurgical management of low-grade astrocytoma of the cerebral hemispheres. J Neurosurg. 1984;61(4):665-73. https://doi. org/10.3171/jns.1984.61.4.0665 PMid:6470776

38. Wu JS, Zhou LF, Tang WJ, Mao Y, Hu J, Song YY, et al. Clinical evaluation and follow-up outcome of diffusion tensor imagingbased functional neuronavigation: A prospective, controlled study in patients with gliomas involving pyramidal tracts. Neurosurgery. 2007;61(5):935-48. https://doi.org/10.1227/01. neu.0000303189.80049.ab

PMid:18091270
39. Cairncross JG, Ueki K, Zlatescu MC, Lisle DK, Finkelstein DM, Hammond RR, et al. Specific genetic predictors of chemotherapeutic response and survival in patients with anaplastic oligodendrogliomas. J Natl Cancer Inst. 1998;90(19):1473-9. https://doi.org/10.1093/jnci/90.19.1473 PMid:9776413

40. Verhaak RGW, Hoadley KA, Purdom E, Wang V, Qi Y, Wilkerson $\mathrm{MD}$, et al. Integrated genomic analysis identifies clinically relevant subtypes of glioblastoma characterized by abnormalities in PDGFRA, IDH1, EGFR, and NF1. Cancer Cell. 2010;17(1):98-110. https://doi.org/10.341 0/f.718384247.793495043

PMid:20129251

41. Stupp R, Taillibert S, Kanner AA, Kesari S, Steinberg DM, Toms SA, et al. Maintenance therapy with tumor-Treating fields plus temozolomide vs temozolomide alone for glioblastoma a randomized clinical trial. JAMA. 2015;314(23):2535-43. https:// doi.org/10.1001/jama.2015.16669 PMid:26670971

42. Brown TJ, Bota DA, van Den Bent MJ, Brown PD, Maher E, Aregawi D, et al. Management of low-grade glioma: A systematic review and meta-analysis. Neuro-Oncol Pract. 2019;6(4):24958. https://doi.org/10.1093/nop/npy034 PMid:31386075

43. Young RM, Jamshidi A, Davis G, Sherman JH. Current trends in the surgical management and treatment of adult glioblastoma. Ann Transl Med. 2015;3(9):121. PMid:26207249

44. Ng WP, Liew BS, Idris Z, Rosman AK. Fluorescence-guided versus conventional surgical resection of high grade glioma: A single-centre, 7-year, comparative effectiveness study. Malaysian J Med Sci. 2017;24(2):78-86.

PMid:28894407

45. Wijnenga MM, Mattni T, French PJ, Rutten GJ, Leenstra S, Kloet $F$, et al. Does early resection of presumed lowgrade glioma improve survival? A clinical perspective. J Neurooncol. 2017;133(1):137-46. https://doi.org/10.1007/ s11060-017-2418-8 PMid:28401374

46. Xia L, Fang C, Chen G, Sun C. Relationship between the extent of resection and the survival of patients with low-grade gliomas: A systematic review and meta-analysis. BMC Cancer. 2018;18(1):48. https://doi.org/10.1186/s12885-017-3909-x PMid:29306321

\section{Author Queries???}

AQ6: Kindly provide expansion if needed.

AQ7: Please note some reference $(13,14,16-25$ and $28-41)$ are not cited in text part and also Please check and cite all references in chronological order. 